\title{
Assessment of the impact of technogenic air pollution on the social processes of large urbanized regions
}

\author{
Sergey Yeprintsev ${ }^{1, *}$, Semen Kurolap ${ }^{1}$, Oleg Klepikov ${ }^{1,2}$, and Syuzanna Shekoyan ${ }^{1}$ \\ ${ }^{1}$ Voronezh State University, 394018, Universitetskaya sq. 1, Voronezh, Russia \\ ${ }^{2}$ Voronezh state University of engineering technologies, 394036, 19 Revolution Avenue, Voronezh, \\ Russia
}

\begin{abstract}
According to the Federal Information Fund for Social and Hygienic Monitoring FCFHE of Rospotrebnadzor air pollution in urbanized cities of Central Russia was studied. The most toxic anthropogenic pollutants and regions with the highest excesses of the maximum one-time and daily average maximum permissible concentrations of anthropogenic pollutants in the urban environment were identified. To assess the impact of technogenic air pollution on the medical and demographic processes of large urban areas in the GIS environment in the studied territories of Central Russia, we studied the dynamics of the general mortality of the population from malignant neoplasms of various organs, as well as the dynamics of mortality from leukemia. Studies have shown that a number of medical demographic processes directly correlate with atmospheric pollution by anthropogenic pollutants.
\end{abstract}

\section{Introduction}

Medical and demographic security is an important criterion for the sustainable development of the territory, and the risks of threats to this criterion are a powerful challenge to modern society. Man-caused air pollution in modern cities entails the massive emergence of environmentally caused diseases of the population, a decrease in the quality of life and other negative consequences [1-4].

The purpose of this study is to assess the impact of technogenic air pollution on medical and demographic processes using the example of urban areas of Central Russia.

The theoretical foundations of the study of the problem of changing medical and demographic conditions during technogenic pollution of the atmosphere of urbanized territories are substantiated in many classical works of Russian-native and foreign scientists on urban ecology, environmental geochemistry and human ecology - by N.S. Kasimov, D.V. Vlasov, N.E. Kosheleva [5], B.B. Prokhorov et al. [6-7], N. Huneeus, H. Denier van der Gon, P. Castesana, C. Menares, R.Y. Ynoue [8], Z. Wang, X. Pan, I. Uno, X. Chen, Z. Wang [9], Y. Ji, X. Chen, Y. Li, W. Zhang, T. An [10], L.M. Mendoza, N. Mladenov, A.M. Kinoshita, F. Pinongcos, R. Gersberg [11], C.-Y. Lin, C.C.K. Chou, Z. Wang, S.-C. Lung,

*Corresponding author: esa81@mail.ru 
Shaw C. Liu [12] and others. In particular, the concept of risk, substantiated in the works of leading Russian-native hygienists G.G. Onishchenko et al. [13-14], B.A. Revich et al. [15] and others, assumes that the combination of potentially hazardous chemicals and other harmful environmental factors in the environment poses a threat to human health. The key link in the concept is public health and its protection against harmful effects through analysis, identification and elimination of risk factors. In recent years, a new scientific field has been rapidly developing, based on the theory of health risks associated with chemical pollution of the environment. It was developed on the basis of joint developments of the Federal Scientific Center for Hygiene named by Erisman, Federal Center for Environmental Policy of Russia and the American Environmental Protection Agency (US. EPA).

\section{Materials and methods}

Evaluation of industrial pollution of the atmosphere, as well as medical and demographic indicators of large urbanized regions, involves working with large geodata arrays, which makes it necessary to use geoinformation resources for conducting the declared studies [13]. Thus, the scientific and methodological approach to the use of GIS technologies for assessing environmental and medico-demographic factors has shown its effectiveness in creating the Medico-Ecological Atlas of the city of Voronezh [1].

Information was collected to characterize the functional planning structure and landscape and environmental conditions for model regions on the basis of special field studies, stock processing material, including cartographic, from regional integrated and sectoral environmental agencies.

For mathematical cartographic modeling, an array of official statistical information was selected for a 20-year period, from 1998 to 2018 [1].

The developed geoinformation resources providing monitoring studies of social and environmental conditions for the population, implemented as part of the GIS, contain 4 sections.

1 Section "Natural Potential".

2 Section "Microclimatic conditions".

3 Section "Socio-environmental conditions."

4 Section Model "Ecological safety of the population."

Based on GIS-maps, a set of environmental-designing measures is being developed to increase the integral indicator of the environmental safety of the population in a particular urbanized area.

Currently, in Russia and in the world there are various approaches to assessing environmental risk for the population living in industrialized cities [1-4].

The environmental risk assessment methodology developed by Professor V. Privalenko is also widely used. It is based on determining the environmental hazard of a territory depending on the content in the atmosphere and soil of different pollutants, taking into account their degree of danger to the population.

This atlas summarizes comprehensive studies of environmental safety factors. [1]. The research involved the leading scientists of the region, as well as representatives of environmental and management structures. The research results have become a powerful reference material in the development of regional environmental policy. [1].

The most informative source of environmental and medical-geographical data on the territory of Russia is the Federal Information Fund for Social and Hygienic Monitoring of Rospotrebnadzor [4].

The study of the medical and demographic potential of the urbanized regions of Central Russia under the influence of technogenic air pollution was carried out according to the methodology for assessing the environmental comfort of the population of urbanized areas 
developed at Voronezh State University [1]. This methodology is based on a comparison of environmental, socio-economic factors, as well as the degree of comfort of environmental conditions [1].

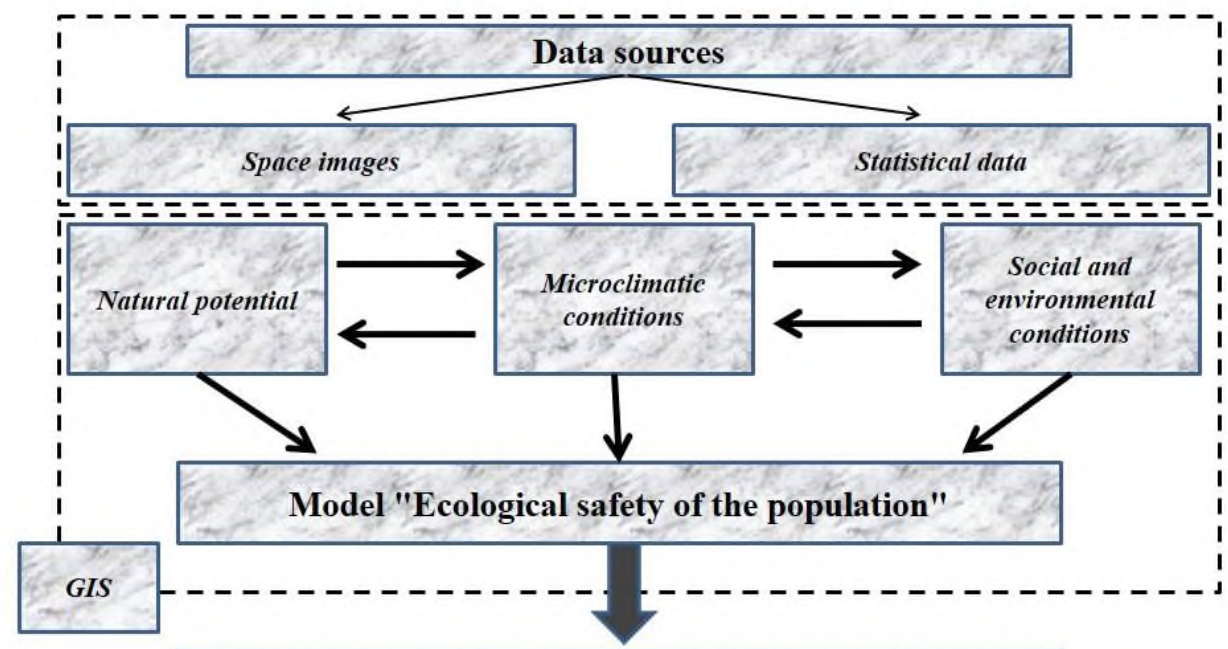

Optimization of environmental quality

Fig. 1. Logical scheme of the GIS "Environmental and socio-economic conditions of urbanized areas of Central Russia".

\section{Results}

The analysis of technogenic atmospheric pollution of urbanized cities of Central Russia, carried out according to the Federal Information Fund for Sanitary and Hygienic Monitoring of the Federal Public Health Institution of Federal Health and Safety at the Federal Service for Supervision of Consumer Rights Protection and Human Welfare showed the presence of excess MPC for a number of pollutants.

An assessment of the specific gravity of daily average atmospheric air samples of the populated areas of Central Russia exceeding hygienic standards in 2017-2019 showed that in a number of cities in the Tver, Tambov, Belgorod regions, as well as in Moscow, there is an excess of maximum permissible concentrations of benzo(a)pyrene, which is a strong carcinogen and belongs to the first class of danger. The main sources of this pollutant are thermal power enterprises, petrochemical and bitumen-asphalt plants, as well as motor vehicle emissions.

In a number of air samples taken on the territory of the city of Moscow, there are observed excesses in the average daily concentrations of formaldehyde MPC. This pollutant is a carcinogen, and can also cause a number of environmentally-related diseases. Moreover, in some samples taken on the territory of the city of Moscow, the concentration of formaldehyde exceeds the daily average MPC by more than 5 times, which cannot but 
cause concern. The main source of formaldehyde air pollution is exhaust emissions from vehicles, as well as industrial emissions.

A significant proportion of air samples taken in the cities of the Belgorod region showed excesses in the average daily concentrations of carbon monoxide, which is a factor in the non-carcinogenic risk of a number of environmentally caused diseases. The main source of this pollutant is vehicle exhaust.

In some samples taken on the territory of the cities of the Voronezh region (mainly in the regional center), the excesses of the average daily MAC of nitrogen dioxide and dust are recorded.

After analyzing the specific gravity of atmospheric air samples in cities of Central Russia with exceeding maximum one-time concentrations, it was found that in the cities of Vladimir and Voronezh regions, almost 20 percent of samples have excess MPCs of dust. It seems possible to explain this fact by intensive construction work in these regions, as well as by the high density of traffic flows. Dust pollution is a non-cancer risk factor for bronchial asthma and other respiratory diseases.

On the territory of the city of Moscow, as well as the cities of the Moscow and Kaluga regions, about 10 percent of atmospheric air samples exceed the maximum one-time MPC of dihydrosulfide (hydrogen sulfide). Moreover, in a number of samples taken in the territory of Moscow, dangerous concentrations of this pollutant are observed (exceeding the maximum one-time MPC by more than 5 times). Atmospheric pollution with hydrogen sulfide is a non-carcinogenic risk of the appearance of diseases of the organs of vision and digestion in the population. The main source of air pollution by hydrogen sulfide is the chemical industry.

In a number of cities of the Central Black Earth region (Voronezh, Kursk and others), excesses in the atmosphere of phenol and formaldehyde are recorded.

To assess the impact of technogenic air pollution on the medical and demographic processes of large urban areas in the GIS environment in the studied territories of Central Russia, we studied the dynamics of total mortality from malignant neoplasms, mortality from malignant neoplasms of the respiratory, digestive diseases, thyroid glands, as well as the dynamics of population mortality from leukemia. In addition, the dynamics of demographic processes, the specific contribution to which atmospheric pollution by anthropogenic pollutants can contribute, the dynamics of infant mortality and the dynamics of general mortality were analyzed.

Analysis of the dynamics of mortality from malignant neoplasms in the cities of Central Russia showed the highest background indicators in the Tula, Bryansk and Oryol regions (table 1).

\section{Discussion}

The highest growth of this indicator over a five-year period (from 2014 to 2018) is observed in Moscow, as well as in the cities of Ivanovo and Tambov regions (table 1). This indicator correlates with air pollution in cities with benzo[a]pyrene and formaldehyde. An assessment of the dynamics of mortality in the cities of Central Russia from leukemia over a five-year period (2014-2018) showed that the highest rates for this factor are observed in the cities of Kursk, Bryansk, Tula and Yaroslavl regions. In the territory of Moscow, as well as the cities of the Tambov, Yaroslavl, Ryazan and Kaluga Regions, there has been a steady increase in mortality from leukemia over a five-year period, which also correlates with air pollution according to several indicators.

In the cities of Tula, Bryansk, Kursk, Kostroma, Kaluga, Belgorod and Vladimir regions, the highest mortality rate from malignant neoplasms of the respiratory system is observed. Steady growth of this indicator over a five-year period was recorded in the cities 
of Bryansk, Belgorod, Lipetsk and Tambov regions, as well as in the city of Moscow. The mortality rate from malignant neoplasms of the respiratory organs correlates with both an excess of the average daily and an excess of the maximum one-time MPC of anthropogenic pollutants in the cities of Central Russia.

Table 1. Dynamics of mortality from malignant neoplasms in 2014-2018 in cities of Central Russia, indicator per 1,000 population Font styles for a reference.

\begin{tabular}{|c|c|c|c|c|c|}
\hline $\begin{array}{c}\text { The subject of the Russian } \\
\text { Federation }\end{array}$ & 2014 & 2015 & 2016 & 2017 & 2018 \\
\hline Belgorod region & 1,88 & 1,89 & 1,91 & 1,85 & 1,88 \\
\hline Bryansk region & 2,23 & 2,36 & 2,34 & 2,32 & 2,41 \\
\hline Vladimir region & 2,00 & 1,91 & 1,95 & 1,80 & 1,79 \\
\hline Voronezh region & 1,44 & 1,67 & 1,41 & 1,51 & 1,55 \\
\hline Ivanovo region & 1,90 & 1,94 & 2,06 & 1,81 & 2,23 \\
\hline Kaluga region & 2,06 & 1,90 & 1,92 & 1,84 & 1,81 \\
\hline Kostroma region & 2,24 & 1,99 & 1,94 & 1,92 & 2,05 \\
\hline Kursk region & 2,22 & 2,23 & 2,23 & 2,13 & 2,00 \\
\hline Lipetsk region & 1,73 & 1,81 & 0,92 & 1,79 & 1,76 \\
\hline Moscow region & 1,61 & 1,56 & 1,50 & 1,24 & 1,33 \\
\hline Oryol Region & 2,23 & 2,28 & 2,21 & 2,25 & 2,24 \\
\hline Ryazan Oblast & 2,29 & 2,31 & 2,19 & 2,04 & 1,06 \\
\hline Smolensk region & 1,93 & 1,85 & 1,83 & 1,91 & 2,07 \\
\hline Tambov Region & 1,27 & 1,40 & 1,39 & 1,33 & 1,38 \\
\hline Tver region & 2,31 & 2,18 & 2,30 & 2,40 & 2,10 \\
\hline Tula region & 2,60 & 2,57 & 2,55 & 2,55 & 2,60 \\
\hline Yaroslavskaya oblast & 2,05 & 2,03 & 2,03 & 2,01 & 2,04 \\
\hline Moscow city & 1,14 & 1,47 & 1,24 & 1,87 & 1,52 \\
\hline
\end{tabular}

From the general demographic indicators, the dynamics of infant mortality should be highlighted. The highest values for a five-year period (2014-2018) for this indicator are observed in the Kostroma, Bryansk, Smolensk, Tula regions and in Moscow. A steady increase in infant mortality over a five-year period stands out in the Smolensk region. Many factors contribute to the formation of this indicator, while the specific contribution of environmental quality is also obvious. [1].

\section{Conclusions}

An assessment of technogenic air pollution in large urbanized regions of Central Russia showed that in most cities there are excesses of daily average and maximum one-time maximum permissible concentrations of anthropogenic pollutants. The most toxic pollutants of the cities of Central Russia are benzo(a)pyrene, formaldehyde, hydrogen sulfide. The largest excesses of the maximum one-time and daily average MPC for various pollutants are recorded in the territory of Moscow, the cities of Moscow, Tambov, Tver, Belgorod, Vladimir and Kaluga regions.

The analysis of medical and demographic indicators of the regions of Central Russia showed a wide range of values within the studied territories. The greatest increase in mortality from the appearance of various malignant neoplasms is recorded in Moscow, as well as in the Bryansk, Belgorod, Lipetsk, Tambov and Kaluga regions.

An assessment of the impact of technogenic air pollution on the medical and demographic processes of large urbanized regions showed that a number of medical and demographic processes directly correlate with atmospheric pollution by anthropogenic pollutants. 
The strongest correlation dependencies were found when atmospheric pollution by benzo(a)pyrene and formaldehyde affected the integral mortality rate from malignant neoplasms, as well as mortality from leukemia.

The study was carried out with the financial support of the Russian Science Foundation, project 20$17-00172$

\section{References}

1. S.A. Yeprintsev, S.V. Shekoyan, L.A. Lepeshkina, A.A. Voronin, M.A., Klevtsova, IOP Conference Series: Materials Science and Engineering (2019)

2. S.A. Yeprintsev, M.A., Klevtsova, L.A. Lepeshkina, S.V. Shekoyan, A.A. Voronin, IOP Conference Series: Earth and Environmental Science (2018)

3. S.A. Yeprintsev, S.A. Kurolap, I.V. Komov, I.V. Minnikov, Life Science Journal (2013)

4. M.I. Chubirko, O.V. Klepikov, S.A. Kurolap, M.K. Kuzmichev, E.M. Studenikina, Radiatsionnaya Gygiena (2019)

5. N.S. Kasimov, D.V. Vlasov, N.E. Kosheleva, Urban Climate (2020)

6. B.B. Prokhorov, D.I. Shmakov, Studies on Russian Economic Development (2013)

7. B.B. Prokhorov, Studies on Russian Economic Development (2011)

8. N. Huneeus, H. Denier van der Gon, P. Castesana, C. Menares, R.Y. Ynoue, Atmospheric Environment, 23515 (2020)

9. Z. Wang, X. Pan, I. Uno, X. Chen, Z. Wang, Environmental Pollution, 234 (2018)

10. Y. Ji, X. Chen, Y. Li, W. Zhang, T. An, Atmospheric Environment, 20915 (2019)

11. L.M. Mendoza, N. Mladenov, A.M. Kinoshita, F. Pinongcos, R. Gersberg, Science of The Total Environment, 71820 (2020)

12. C.-Y. Lin, C.C.K. Chou, Z. Wang, S.-C. Lung, Shaw C. Liu, Atmospheric Environment, 60 (2012)

13. N.V. Zaitseva, G.G. Onishchenko, A.Y. Popova, D.A. Kiryanov, M.V. Glukhikh, Health Risk Analysis (2019)

14. Y.A. Rakhmanin, G.G. Onishchenko, Y.G.Grigoriev, Gigiena i Sanitariya (2019)

15. B.A. Revich, Studies on Russian Economic Development (2020) 